\title{
1. At the crossroads of long-term development
}

It was the spring of hope, it was the winter of despair. (Charles Dickens)

For many years, economists, scholars across broadly diverse academic fields, and amateur observers have made various predictions on the Chinese economy, either praising or criticizing, which frequently draw the attention of the Chinese government and are the source of hot debates in the media and academia. Though some of these predictions are not based on rigorous, scientific analysis, they all serve as a wake-up call to warn of problems which pose challenges to Chinese economic growth and to suggest solutions.

This book, however, only cites predictions based on methodologically sound studies, while ignoring those "crying wolf" stories that are popular but not backed by sufficient evidence or economic rationale. Furthermore, predictions and forecasts on the macroeconomic cycles of China are not included within the scope of this discussion, because in the short run the macroeconomy fluctuates as external shocks come and go, the government changes direction on macroeconomic policy, and people alter their expectations. By reviewing existing predictions on the Chinese economy and other economies' slowdowns that are relevant to China, this chapter asserts that the Chinese economy is standing at a crossroad that divides its future prospects.

\subsection{PROSPECTS OF THE CHINESE ECONOMY}

Immediately after 2010, when China surpassed Japan to become the second-largest economy in the world, the question arose as to when China would surpass the United States to become the world's number one economy. As can be expected, a host of studies have emerged to predict China's next step. The most optimistic prediction made by the International Monetary Fund (IMF) asserts that, based on purchasing power parity (PPP), the total GDP of China will increase to 19 trillion US dollars in 2016, accounting for 18 percent of the world's GDP, whereas 
the total GDP of the United States will be only 18.9 trillion US dollars, accounting for 17.7 percent of the world's GDP (IMF, 2011). Similar studies by some other authorities have vindicated such a projection - that is, China will eventually surpass the United States and become the largest economy in the world.

Such a vision is not an imaginary story from Arabian Nights, but a natural extrapolation of the future based on previous trends. In 1990, China was only ranked as the world's tenth-largest economy. In 1995, its GDP volume surpassed that of Canada, Spain, and Brazil to be ranked as seventh in the world, and soon afterwards, in 2000, it further surpassed Italy to be sixth. In the first decade of the twenty-first century, China has successively outstripped France, the United Kingdom, Germany, and Japan to become the second-largest economy in the world.

An immediate reflection on this trend is that, as China has the world's largest population, accounting for a fifth of the world's total population, becoming the largest economy in the world is nothing to boast about. However, many researchers are quite optimistic about the per capita income of China in their predictions. For example, Robert Fogel, the Nobel Prize laureate in economics, estimates that, in 2040, China's GDP will total 123.7 trillion US dollars in PPP terms, accounting for 40 percent of the world economy. As its population will reach 1.46 billion at that time, the per capita GDP in China will be 85000 US dollars, which is 2.4 times the world average per capita GDP and 80 percent of the United States' per capita GDP (Fogel, 2007). As a matter of fact, according to a prediction by the United Nations, China's total population will peak at 1.44 billion in 2035 and then decline to 1.43 billion in 2040. Based on the population census conducted in 2010, the total population of China will peak at 1.38 billion in 2020 and decline to 1.3 billion in 2040. Divided by the newly predicted population, the per capita GDP of China will be much closer to that of the United States in 2040. Such prospects are hardly surprising if one looks closely at the Chinese economy's past 30-plus years of high growth rates.

After the eighteenth century, while western countries sped up their economic progress, Chinese economic growth greatly lagged behind. In the period from 1700 to 1820 , the annual GDP growth rate was only 0.85 percent, and per capita GDP had no growth at all in China. For several decades before the People's Republic of China was established in 1949, the country had experienced domestic trouble and foreign invasion, economic stagnation, and extreme destitution. In the period 1820 to 1952, the annual growth rate of GDP was 0.22 percent and that of per capita GDP was -0.08 percent, compared to 1.71 percent and 1.03 percent, respectively, in Europe. 
During the entire pre-reform period - namely, the period from 1950 to 1978 - China failed to catch up with the world's developed and newly industrialized economies, struggling under the implementation of a central planning scheme characterized by a refusal of market mechanisms, excessive capital accumulation, and an imbalance in its industrial structure, along with frequent political movements that harmed overall economic growth. In fact, the gap in living standards between China and the rest of the world not only did not grow more narrow, but actually widened. In 1978, there were 250 million rural residents living below the absolute poverty line.

Since the late 1970s, China has undergone fundamental institutional changes, which include the abolition of the People's Commune system and introduction of the household responsibility system in rural areas, transformation of the resources allocation mechanism from a planning system to a market force-based system, and moving from a closed economy to participating in the global economy. As a result of such a process of reform and opening-up, market-based and effective economic institutions, such as incentive mechanisms, modern corporate governance, the public fiscal system, rival financial and banking systems, and a social security system, have all been established.

All these achievements are ultimately reflected in the strengthening of China's national power and the improvement of people's livelihood. In the period spanning 1978 to 2012, China achieved an annual GDP growth rate of 9.8 percent. Not only has the Chinese economy caught up with those of the world's economic powers in terms of size, but people's income has increased at a miraculous pace - the annual growth rate of GDP per capita in this period was 8.7 percent (Figure 1.1).

In what follows, we can compare the time span of China doubling its per capita GDP with that of more-developed forerunner countries at comparable stages of economic development. Historically, the doubling of per capita GDP took 58 years (1780-1838) in the United Kingdom, 47 years (1839-1886) in the United States, 34 years (1885-1919) in Japan, and 11 years (1966-1977) in South Korea. For China, however, the doubling of per capita GDP took only 9 years (1978-1987), 8 years (1987-1995), 9 years again (1995-2004), and 7 years (2004-2011).

In their book The China Miracle, the Chinese edition of which was first published in 1994, Justin Yifu Lin, Fang Cai, and Zhou Li (2003) forecast that, if the differential growth rates in China, Japan, and the United States remain unchanged as they were between 1980 and 1995, the size of the Chinese economy will surpass that of Japan and the United States in 2035, based on constant price and exchange rates, and that the surpassing will occur in 2015 if the forecast is based on purchasing power parity. 


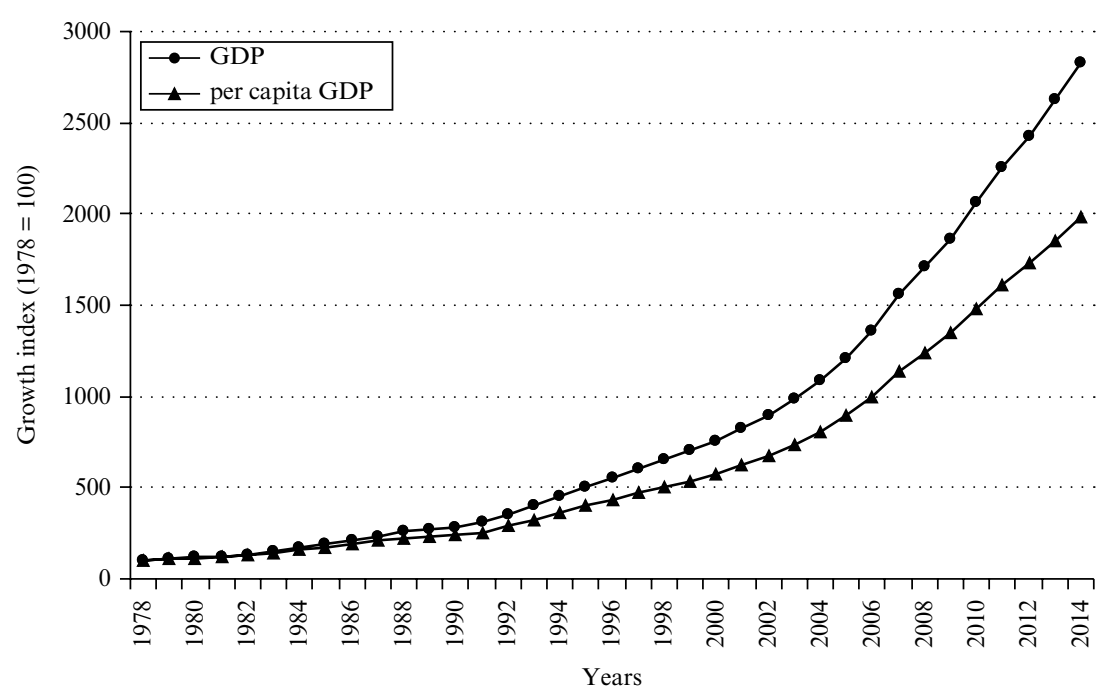

Source: National Bureau of Statistics (2014).

Figure 1.1 Economic growth rate in China's reform period

Lawrence Summers, the American economist, the Department of Foreign Affairs and Trade of Australia, Angus Maddison, the British economist and expert on quantitative macroeconomic history, and the World Bank all made similar predictions (Lin et al., 2003).

Since the beginning of the twenty-first century, most international organizations and economists, except for a small handful of what are called "China collapse fortunetellers," have held the belief that China will become the world's largest economy earlier than previously predicted. The debate on whether China can achieve this goal is now beyond just a matter of economic ranking, but is, rather, about whether China may become the only country in world history to have fallen from the zenith of human civilization into the trough and again climb to the apex.

\subsection{FROM GREAT DIVERGENCE TO GREAT CONVERGENCE}

In one of its reports, the World Bank expressed high expectations of the East Asian economies, which are called "the East Asia project" (Gill and Kharas, 2007). That is, the region is expected to grow 5.9 percent annually, 
much higher than the world average growth, and its share of GDP is expected to increase to account for 40 percent of the world total by 2025 . In that case, East Asia will return to the historical glory held by the region in 1820. In view of the size of the Chinese economy and its contributive share in East Asia, China will play an overwhelmingly important role in the East Asia project.

In the field of world economic history, scholars have reached a consensus that the existing pattern of the world economy - namely, the absolute dominance of Europe and its western offshoots in economic development, technology, and per capita income - was not always so. The so-called California school of historical studies asserts that, around 1500, the world's wealth was mainly concentrated in the east, where China took the lion's share, and it was only as recently as 1750 that a great divergence occurred between the east and the west (Pomeranz, 2000; Goldstone, 2008).

Paralleling the course of this great divergence, the gaps in economic prosperity, scientific and technological progress, and standard of living between China and the west significantly widened as China became widely known as a poor and weak country. With intense debate on why the east lagged behind during the period following the industrial revolution, the "Needham Puzzle" - that is, why China had been in an advantageous position in scientific and technological developments compared to western countries in pre-modern times, yet lagged behind its western counterparts after the industrial revolution - became a sub-topic of a larger question, the "Puzzle of the Great Divergence."

China had been the country with the world's most advanced and prosperous science, technology, and economy for over 1000 years, until the industrial revolution swept the western world in the late eighteenth century and early nineteenth century. Historical studies find that China's agricultural productivity was among the world's highest from the ninth century through the thirteenth century, that its industry was the most developed in the world from the Han dynasty through the fourteenth century, and that its urbanization level - representing the development of commerce-was advanced compared to Europe's during the middle of the Song dynasty. Accordingly, various economic institutions relating to market development were well developed during those periods. Only after the sixteenth century did the economic development and technological advancement in China begin to lag behind that of European countries. ${ }^{1}$

Not only did domestic turmoil and foreign aggression impede China's economic development before 1949, when the People's Republic was established, but a series of political movements and failure of economic policy also delayed China's catch-up with more developed countries. According to one scholarly estimation, the Great Leap Forward and the Cultural 
Revolution caused a 63 percent reduction of labor productivity (Kwan and Chow, 1996). Towards the end of the Cultural Revolution in the late 1970s, Chinese leaders realized that not only was the gap between China and western countries continuing to widen but China also lagged far behind other neighboring Asian economies, including its own territories such as Taiwan, Macau, and Hong Kong.

The mistakes made during the first three decades of the People's Republic of China led China to miss the opportunity for the great convergence, which allegedly started in 1950, according to Michael Spence, a Nobel laureate in economics (Spence, 2011). That is, the Chinese economy lost three decades' worth of economic growth. With economic reform initiated in the early 1980s, unprecedented fast growth has revived the Chinese economy and catapulted it to the world's second largest within three decades. Given the size of China's population and GDP, this dramatic reversal has led the world economy to another round of great convergence.

In his prominent works, Angus Maddison, the late economic historian, provides a widely citable, comparable dataset of total GDP and GDP per capita of major countries dated from an early point in human history. By updating Maddison's historical data, we now have a complete picture of China's share in the world's economy and its income level relative to the world average (Figure 1.2), which can, in a highly condensed manner, depict the fall and rise of the Chinese economy in history.

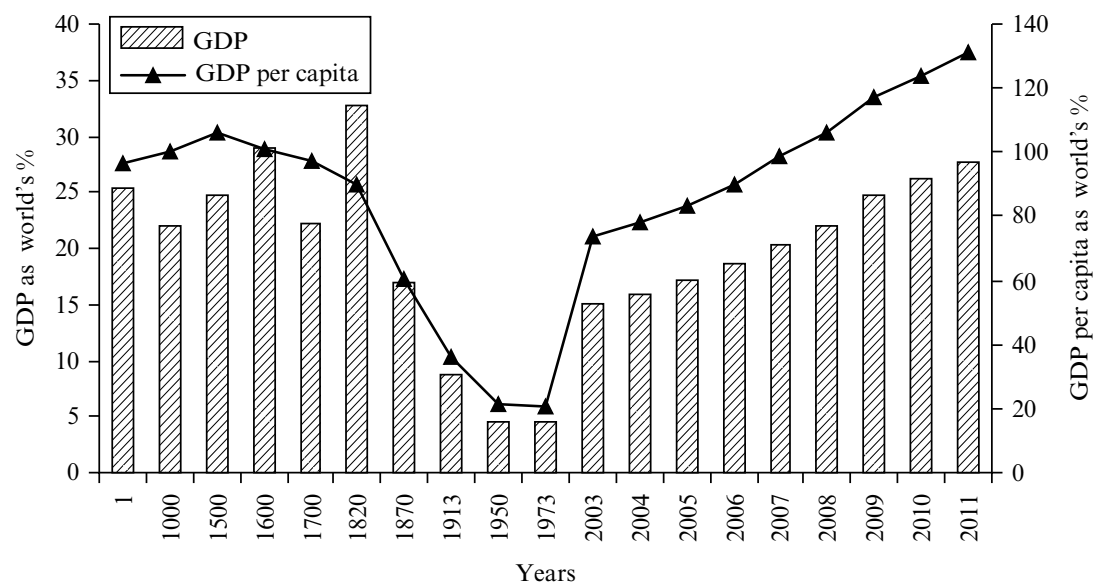

Source: Maddison (2007).

Figure 1.2 China's comparative economic size and income level in the world 
Historically, in terms of China's standing in the world economy, its per capita income peaked in 1500 , being 6 percent higher than the world average, and its GDP peaked in 1820, making up nearly one-third of the world's total. Figure 1.2 clearly shows that the share of the Chinese economy in the world has experienced a continuous increase since the early 1980s, after it had declined and bottomed out for more than one and a half centuries. That is, the data of this long history indicate a V-shaped change in the Chinese economy; the fall began in the nineteenth century, and the renaissance as the result of China's reform and opening-up.

\subsection{FAILURE OF THE NEOCLASSICAL PREDICTION OF CONVERGENCE}

An essential assumption about the neoclassical theory of growth is the law of diminishing return to capital. That is, given that the labor supply is limited, as physical capital is invested in the production process, its marginal return tends to decline. Therefore, less-developed countries may grow faster than more-developed countries. If such a differential in the growth rate between less- and more-developed countries lasts for a sufficiently long time, economic convergence among countries will occur. The implication of this theoretical prediction is that economically lagging countries potentially have the chance to catch up with their more advanced counterparts.

A host of observations and studies, however, do not confirm the hypothetical convergence between developing and developed economies. Instead, the facts show that, with a few exceptions in East Asian economies that have successfully caught up to their forerunners, the more advanced countries have in general grown faster than less-developed countries. The convergence has not happened and, what's more, the gap has instead widened. ${ }^{2}$ On the other hand, the neoclassical theory of growth does not accurately predict or explain the distinct examples of economic catching-up, first in East Asia and, very recently, across a wider range of developing countries. There are three reasons for the failure of the neoclassical theory of growth.

First, a widely recognized fault of the neoclassical theory of growth lies in its treatment of technological progress as an exogenous factor, so that an important (virtually the only) source of long-term growth is excluded from its theoretical model. Growth theorists have tried to fill the gap by incorporating factors such as technological progress into their theoretical model. For example, the new theory of growth represented by Paul Romer, Robert Lucas, and others, which identifies the roles of human capital accumulation and technological innovation, has revitalized the theory 
of growth. Once human capital characterized by increasing returns and technological innovation and diffusion tending to generate monopolies are endogenized into the growth model, the assumption of perfect competition by neoclassical theory of growth has been broken.

Second, the neoclassical theory of growth simplifies economic growth as the result of the input of production factors and the enhancement of total factor productivity (TFP), and treats the latter as a statistical "residual," while simultaneously neglecting peculiar institutional features of countries at different stages of development. Empirically, scholars recognize a phenomenon of convergence clubs, which is that countries or regions with homogeneity - such as member states of the Organisation for Economic Co-operation and Development (OECD), states within the United States, or the counties of Japan - tend to converge in economic growth, whereas countries and regions with heterogeneity tend to diverge. These empirics, which partially confirm and partially reject the convergence assumption of the neoclassical theory of growth, have helped to form a new concept - the conditional convergence.

In fact, the neoclassical theory of growth implicitly suggests a conditional convergence. For example, it recognizes that the differences in population growth rate and in propensity to saving generate different long-term growth rates among countries. Only when those conditions are assumed to be constant can countries at a low starting point grow more quickly, which is necessary for convergence. Based on such a tradition of neoclassical theory of growth, Barro and Sala-i-Martin (1995) have put various variables in their empirical model of growth regression, having identified relevant conditions for convergence in trying to test the conditional convergence hypothesis. ${ }^{3}$

Both the new growth theory and the neoclassical theory of growth have their role in explaining the growth performances of countries. On the one hand, economists like Romer (1986) and Lucas (2009) point out how increasing returns can sustain the growth of developed countries, which also has implications for economies in the process of catching up. On the other hand, economists like Barro and Sala-i-Martin (1995) have found more than a hundred variables (factors) that have a significant impact on the growth performance of countries, positive or negative. These -including the level of savings and investment, infrastructure, institutions, government responsibility, human capital, and other demographic characteristics-are necessary conditions if lagging countries are to catch up.

Third, the neoclassical theory's assumption of labor scarcity and a diminishing return to capital is not appropriate for many developing countries. Based on empirical studies by certain economists in the early 1990s, Paul Krugman (1994), who won the Nobel Prize in Economics years 
later, criticized the East Asian model. Taking Singapore as an example, he asserted that the rapid growth in those economies could be solely attributed to the accumulation and input of production factors but not to the improvement of productivity. He therefore prophesied that such a growth pattern would not be sustained, much as had happened in the former Soviet Union.

The long-term growth performance of Singapore and other East Asian Tigers proves the failure of Krugman and his neoclassical colleagues' predictions, because they wrongly applied the neoclassical assumption to the growth patterns of the East Asian economies characterized by dual economy development coupled with an unlimited supply of labor, which not only broke the law of diminishing return to capital, but also created resources' reallocative efficiency through labor mobility from the low-productivity (agricultural) sector to the higher-productivity (nonagricultural) sectors.

In addition to the World Bank's publications, which are intended to generalize rather than modeling any specific East Asian experiences and lessons in economic development (e.g. World Bank, 1993), and inexorable criticism on the same experiences by neoclassical theorists of growth (for example Krugman, 1994), there has been a host of literature employing an analytical framework that is wholly unorthodox to the neoclassical approach of theorizing East Asian development.

For example, Kojima (2000) extends the early "flying geese paradigm" to a more thorough theoretical model in order to explain the catch-up process of the East Asian economies and the outward-oriented growth led by trade and foreign direct investment. As admitted by Kojima himself, however, such a model is yet incomplete in explaining economic growth in East Asia. More recent work trying to explain East Asian economies' catch-up can be seen in an example by Aoki (2012). By dividing economic development in this region into five successive phases and endogenizing institutional factors, he tries to explore the commonality of economic development patterns and the difference of institutional evolutionary paths among China, Japan, and South Korea. What he implies is that, given the path dependence of institutional evolution in different countries, imitating the western model does not guarantee any degree of success.

It is not hard to comprehend the China experience as long as one recognizes the limitation of conventional theories, grasps the commonalities and differences among developing countries, and knows the history of China's reform. The miraculous convergence of China with developed economies in the level of economic development and standard of living over the past three decades proves that, conditioned by the correct choice of development pattern in accordance with the unique features of the country, 
latecomer countries are bound to catch up with their more advanced counterparts after all. On the other hand, only if an economic theory is tested by practice can it be proven valid. The experiences shown in the successful reform, opening-up, and resulting rapid socioeconomic development of China, therefore, are much more meaningful than 2 million econometric regressions by growth theorists in testing a convergence hypothesis. ${ }^{4}$

\subsection{WHEN AND WHY DOES FAST GROWTH SLOW DOWN?}

The exciting predictions widely offered by many international institutions for the Chinese economy based on its past performance do not guarantee future sustainable growth. One cannot help comparing China with Japan when thinking about the sustainability of rapid economic growth. The Japanese economy was widely viewed to be bullish in long-run growth, manifested in the fact that it became the world's second-largest economy in the late 1980s. Japanese economic growth, however, has been stuck in "the lost two decades" or so since 1990, and Japan lost its position as the world's second-largest economy in 2010.

In a burst of appreciation and recognition for China's unprecedented economic achievements, some studies have appeared that aim to predict when, under what circumstances, and to what extent Chinese economic growth could slow down. On the basis of the statistical law of "regression to the mean," which asserts that any phenomenal economic growth will eventually return to the world average growth rate, Pritchett and Summers (2014) estimate that China's annual growth rate will be 5.01 percent in the period 2013-2023 and further drop to 3.28 percent in the years 2023-2033. Methodologically, a similar study was done by Eichengreen and his coauthors, which was intended to answer the questions of when rapidly growing economies - namely, at what level of per capita income - would slow down and what such experiences would imply for China (Eichengreen et al., 2011). Its findings are twofold. One, when fast-growing catch-up economies reach a per capita GDP of 17000 US dollars measured by year 2005 international prices, they tend to slow down by 3.5 percentage points on average. Two, as China will soon reach this threshold, the probability is great that China will follow the same path sometime after 2015.

The slowdown in growth as revealed by studies of this kind is not necessarily a bad thing. Whether it is a natural trend or undesired outcome depends on the causes of each economy's slowdown. As Russian novelist Leo Tolstoy put it, happy families are all alike; each unhappy family 
is unhappy in its own way. While countries may share common causes, each individual country also has its own particular causes for suffering a slowdown of growth. For China, which has benefited from a demographic dividend throughout its entire reform period, the dramatic change in population trends is a critical force slowing growth. Such a characteristic outcome is generally expressed as "growing old before getting rich."

As a result of long being at a demographic transition phase with low fertility, China has witnessed a tremendous change in the age structure of its population. According to the 6th National Census, the population aged between 15 and 59 peaked in 2010 and has had negative growth since then. It is predicted that in the period from 2010 to 2020 the population within this age group will decrease by 29.3 million, which can be considered a significant decline in the labor supply. Primarily based on reversed population trends, the potential GDP growth rate is estimated to decline from 10.3 percent over the 1995-2010 period to 7.6 percent in the 2011-2015 period and 6.2 percent in the 2016-2020 period. That is, the year 2010 is the specific threshold for economic slowdown in China.

In terms of the year 2005 international dollar used by Eichengreen and others, in 2010 China's per capita GDP was 11466 US dollars. It seems that there is little similarity between the China of the year 2010 and Japan of the year 1992 in terms of at what development stages they stand, because, although Japan encountered its slowdown threshold in that year, its comparable per capita GDP was 27250 dollars, 1.38 times higher than China's in 2010. However, given that both China and Japan used to enjoy an opportunity window of population dividends and started slowing down in growth when demographic transition entered a new stage, at which point the working-age population began declining and the dependence ratio increasing, comparing China in 2010 to Japan in 1992 remains relevant for understanding the slowdown story.

Not coincidently, at the slowdown threshold, the dependence rationamely, the ratio of the population aged 14 and younger and 65 and older to the population aged 15-64 in Japan-began to increase dramatically. As shown in Figure 1.3, first, the Japanese economy has actually had two slowdowns, one being in the early 1970s and another in the early 1990s, along with the change in its demographic profile, and, second, the later slowdown was revealed as stagnation for quite a long period.

Three things should be emphasized about China's slowdown. First of all, although the reversal of population trends may be the key cause leading to slower growth, there are other factors that also matter. While researchers can name many such factors, the lessons from those economies-which experienced economic slowdown followed by falling into a middle-income trap-show that development strategies and social policies that are starkly 


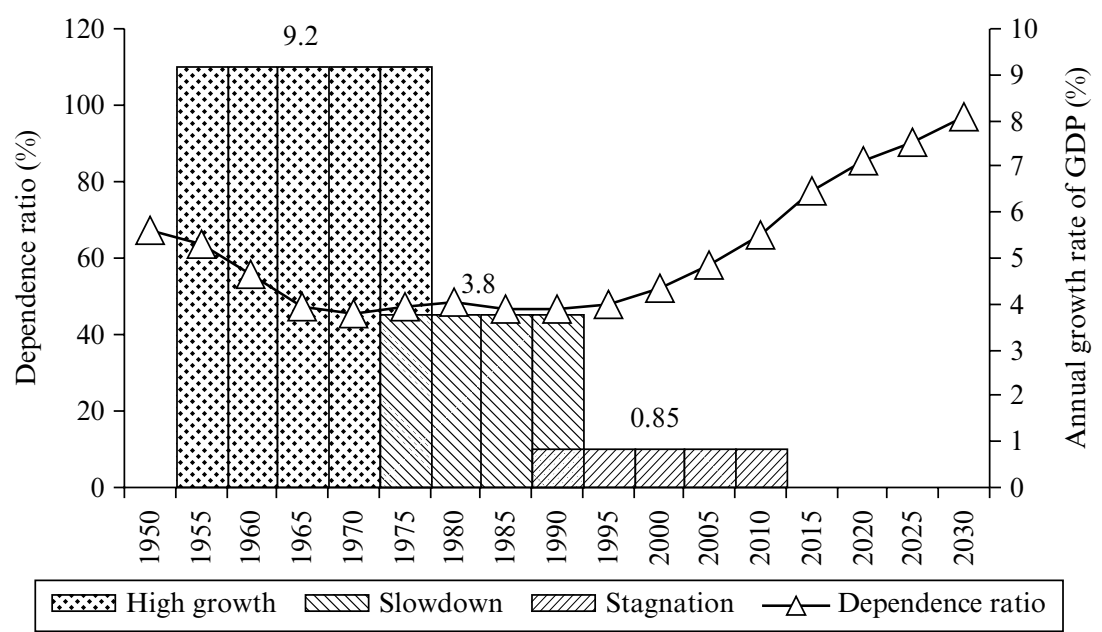

Source: Population data are from the UN, and GDP data are from the World Bank, and Hoshi and Kashyap (2011).

Figure 1.3 Japan's slowdown and stagnation along with its demographic transition

different from those previously employed must be chosen during a country's transition from the middle-income to the high-income phase. ${ }^{5}$

Secondly, if just following the average path of economic slowdown in the history of development-namely, if the growth rate drops by 3.5 percentage points, as is proposed by Eichengreen and others - China can still maintain its position as a rapidly developing economy. For example, even a slowed annual growth rate of 6.3 percent, compared to 9.8 percent during the period $1978-2012$, is still reasonable. So, what matters to China is to avoid the economic stagnation that can be caused by misdealing in the face of such a slowdown.

Finally, while taking the place of Japan as the second-largest economy in the world in 2010, China just joined the upper-middle-income group, and the per capita GDP in China was only 42.1 percent of that in Japan in 1992. That is, unlike Japan's stagnation in the lost decades after its slowdown threshold, which can be viewed as a "high-income trap," if China falls into a rut it would become another example of the "middle-income trap" common among many developing economies, typically in Latin America and Southeast Asia.

In order to avoid such a worst-case scenario, China has to awaken from its past success and be prepared to meet the challenges it will face when 
its economic growth is bound to slow down. The issue is not whether the fast growth in China will slow down, but how China should live with a more moderate growth and prevent stagnation. Luckily, there have been a host of lessons from both successful and failed experiences in economic history.

\subsection{CONCLUSION}

International experiences show that the threshold for the slowdown in economic growth actually serves as a watershed dividing countries into three very different scenarios. In what follows, we simplify such scenarios, which can no doubt provide important implications for how China can strive for the best result and avoid the worst.

The United States and European countries are typical examples of the first scenario. Although these countries no longer grow as quickly as they previously did before reaching the threshold, they still remain pioneers on the scientific and technological frontier in order to sustain qualitative economic growth. For example, based on elements of the national economy that enable innovative activities, such as institutions, human capital and research, infrastructure, market and business sophistication, knowledge and technology outputs, and creative outputs, the top 20 economies in the ranking of the global innovation index in 2013 are all European and North American countries with the additions of Hong Kong (China), Singapore, South Korea, and Israel. ${ }^{6}$

This bright side indicates that although developing countries have the opportunity to take advantage of backwardness in their fast-growing stages of development - namely, they can borrow, purchase, and imitate applicable technologies from advanced countries - they eventually have to rely on independent innovation to sustain their long-run growth, which is particularly true following the slowdown threshold.

Even if there is a gradual slowdown due to the disappearance of its demographic dividend, if China can accomplish a transition from an input-driven growth pattern to a productivity-driven growth pattern its economy will continue to increase in quality and sustainability. While there is an urgent need for China to innovate more independently as it enters the new stage of development, the already-existing significant gap in sciences and technology between China and more advanced economies will still be able to furnish China with the advantage of backwardness - that is, China does not necessarily invent applied technologies in every area, but it can borrow them cheaply, which will enable China to grow more rapidly than its developed counterparts in the next decade or so. 
Japan can serve as a perfect reference for the second scenario. Incorrectly coping with the inevitable changes in its development stages, Japan has turned its natural economic slowdown into an artificial stagnation since the early 1990s. Even though Japan still holds its place as the world's third-largest economy, with the highest income per capita in world rankings, its ability to innovate and influence the world economy has been diminishing over time. For instance, Japan's rank in the global innovation index in 2013 was downgraded to 22nd, not only after the most advanced North American and European countries, but also after its Asian neighbors-Hong Kong (China), Singapore, and South Korea.

The "lost two decades" story of Japan suggests that it is not the natural slowdown as a result of changes encountered during the development stages, but the policy choices in coping with such a slowdown that leads a country to different scenarios. In the face of a weakened potential growth rate, there is the temptation for China to make policy efforts to stimulate the economy through demand-side factors while failing to enhance its potential growth capability through supply-side factors, which may lead China to share the fate of Japan. Therefore, properly combining policy measures that cope with both short-term macroeconomic shock and longterm sustainability of growth is crucial for China at this crossroad.

Some Latin American and Southeast Asian countries represent the third scenario. Although many of them became middle-income countries long ago, they have never been able to catch up with the world's more developed countries in terms of per capita income. That is, they have been stuck in the middle-income trap. There are four sequences of their undesirable economic and social developments: (1) the failure of economic policies and institutions hinders economic growth, preventing a country's economic "pie" from enlarging; (2) the constant size of the pie cannot be equally shared among all groups within a population; (3) vested interest groups attempt to influence policy making to keep their bargaining power in determining income distribution; and (4) politicians only pay lip service to change instead of really altering their populist socioeconomic policies.

The middle-income trap scenario clearly shows that economic growth, income distribution patterns, and policies and institutions that influence income distribution are closely interdependent and interrelated with each other as both cause and effect. Up until now, China has witnessed shared growth in general. Even though there is growing concern regarding income inequality, it can still be tolerated as long as the economic pie is enlarging. Furthermore, as far as labor income is concerned, there has been a trend towards a reduction in inequality. Only if stagnated growth provided nothing to distribute among all groups while the most influential 
group received an even larger share of income would there be strong dissatisfaction towards the distributive pattern, which would inevitably lead to social unrest.

The Chinese leadership has been preparing for a slower, shared growth. In the 12th Five-Year Plan, the goal of the annual growth rate of China's GDP is set to be 7 percent, lower than that in the country's previous FiveYear Plans. Such a growth rate gives China more room to transform its economic growth pattern and to focus more on people's livelihoods. In what follows in this book, the theme of avoiding the middle-income trap is not about avoiding an economic slowdown entirely, but about keeping away from falling economic stagnation by tapping new sources of growth.

\section{NOTES}

1. About the concept of the Needham Puzzle and some comparative facts between early China and Europe, see, for example, Lin (2008).

2. Since the beginning of the twenty-first century, the growth performance of emerging markets has shown signs of reversal of the long-lasting divergence. However, whether such a trend can last requires further observation. The purpose of this book is to offer answers on why the convergence has happened and how it can continue by inquiring into the Chinese experience.

3. See, for example, Barro and Sala-i-Martin (1995).

4. Sala-i-Martin, a Spanish-born American professor, once used the title "I Just Ran Two Million Regressions" to describe his academic efforts in testing the convergence hypothesis of the neoclassical theory of growth. See Sala-i-Martin (1997).

5. See, for example, Gill and Kharas (2007).

6. http://globalinnovationindex.org/content.aspx?page=data-analysis.

\section{REFERENCES}

Aoki, Masahiko (2012), "The Five Phases of Economic Development and Institutional Evolution in China, Japan, and Korea," in Masahiko Aoki, Timur Kuran, and Gérard Roland (eds.), Institutions and Comparative Economic Development, Basingstoke: Palgrave Macmillan, pp. 13-47.

Barro, Robert, and Xavier Sala-i-Martin (1995), Economic Growth, New York: McGraw-Hill.

Eichengreen, Barry, Donghyun Park, and Kwanho Shin (2011), When Fast Growing Economies Slow Down: International Evidence and Implications for China, NBER Working Paper No. 16919, Cambridge, MA: National Bureau of Economic Research.

Fogel, Robert (2007), Capitalism and Democracy in 2040: Forecasts and Speculations, NBER Working Paper No. 13184, Cambridge, MA: National Bureau of Economic Research.

Gill, Indermit, and Homi Kharas (2007), An East Asian Renaissance: Ideas for Economic Growth, Washington, DC: World Bank. 
Goldstone, Jack (2008), Why Europe? The Rise of the West in World History, 1500-1850, New York: McGraw-Hill.

Hoshi, Takeo, and Anil Kashyap (2011), "Why Did Japan Stop Growing?," report prepared for the National Institute for Research Advancement (NIRA), http:// www.nira.or.jp/pdf/1002english_report.pdf.

IMF (International Monetary Fund) (2011), World Economic Outlook Database, April, https://www.imf.org/external/pubs/ft/weo/2011/01/weodata/index.aspx.

Kojima, Kiyoshi (2000), "The 'Flying Geese' Model of Asian Economic Development: Origin, Theoretical Extensions, and Regional Policy Implications," Journal of Asian Economics, 11, 375-401.

Krugman, Paul (1994), "The Myth of Asia's Miracle," Foreign Affairs, 73 (6), $62-78$.

Kwan, Yum, and Gregory Chow (1996), "Estimating Economic Effects of Political Movements in China," Journal of Comparative Economics, 23, 192-208.

Lin, Justin Yifu (2008), "The Needham Puzzle, the Weber Question, and China's Miracle: Long-Term Performance since the Sung Dynasty," China Economic Journal, 1 (1), 63-95.

Lin, Justin Yifu, Fang Cai, and Zhou Li (2003), The China Miracle: Development Strategy and Economic Reform, rev. edn., Hong Kong: Chinese University Press of Hong Kong.

Lucas, Robert (2009), "Ideas and Growth," Economica, 76 (301), 1-19.

Maddison, Angus (2007), Contours of the World Economy, 1-2030 AD: Essays in Macro-economic History, Oxford: Oxford University Press.

National Bureau of Statistics (2014), China Statistical Yearbook 2014, Beijing: China Statistical Press.

Pomeranz, Kenneth (2000), The Great Divergence: Europe, China, and the Making of the Modern World Economy, Princeton, NJ: Princeton University Press.

Pritchett, Lant, and Lawrence H. Summers (2014), Asiaphoria Meets Regression to the Mean, NBER Working Paper No. 20573, Cambridge, MA: National Bureau of Economic Research.

Romer, Paul M. (1986), "Increasing Returns and Long-Run Growth," Journal of Political Economy, 94 (5), 1002-1037.

Sala-i-Martin, Xavier (1997), "I Just Ran Two Million Regressions," American Economic Review, 87 (2), 178-183.

Spence, Michael (2011), The Next Convergence: The Future of Economic Growth in a Multispeed World, New York: Farrar, Straus and Giroux.

World Bank (1993), The East Asian Miracle: Economic Growth and Public Policy, World Bank Policy Research Report, Oxford: Oxford University Press. 